\title{
Internisten der Schweiz, vereinigt euch ...
}

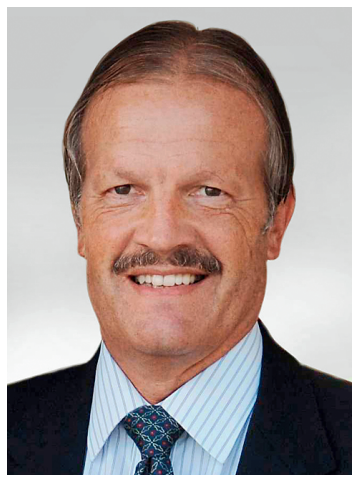

Ulrich Bürgi ...vom 13. bis 15. Mai 2009 an der Jahresversammlung der SGIM in Basel!

Das Tagungsmotto «Von der klinischen Forschung zum Praxisalltag» ist für alle an Innerer Medizin Interessierten - vom Forscher zum Spitalmediziner über den internistischen Doppeltitelträger bis hin zum Einzelkämpferhausarzt im gern zitierten hintersten Bergtal - hochrelevant. Über 200 Referenten, Seminar-, Workshopleiter, Moderatoren und Learning-Center-Instruktoren werden alle ihre rhetorischen und didaktischen Register ziehen, um das Lernen für die Tagungsteilnehmer zum Vergnügen werden zu lassen.

Als Präsident der SGIM ist es natürlich meine Pflicht und mir obendrein eine grosse Freude, Sie zur Teilnahme an unserer Jahresversammlung zu animieren. Es gibt aber ganz abgesehen davon, dass ich für einen so wichtigen Kongress gerne die Werbetrommel rühre, eine ganze Reihe triftiger Gründe, die die Teilnahme an unserer diesjährigen Jahrestagung zu einem Muss machen:

- Das Tagungsthema «Forschung/Praxis» ist von höchster Aktualität: Die wachsende Diversifizierung der (Inneren) Medizin betrifft nicht nur die klinischen Bereiche, sondern auch die Forschung. Das gegenseitige Sichverstehen von Forschern und Klinikern wird deshalb schwieriger. Die immer komplexeren Forschungsmethoden sind für den Kliniker oft nicht mehr ohne weiteres verständlich und machen seine Beurteilung von Forschungsresultaten schwierig. Dies betrifft nicht etwa nur die Grundlagen-, sondern auch die klinische Forschung: Hierfür wichtige Grundbegriffe, wie z.B. der Epidemiologie, müssen dem Kliniker geläufig sein. Wer der Ansicht ist, Kohorten hätten einzig etwas mit römischen Legionen zu tun, hat Nachholbedarf. Anlässe wie die SGIM-Jahresversammlung 2009 bieten für den Kliniker eine ausgezeichnete Gelegenheit, sein Forschungsverständnis zu erweitern. dent (Vorsitzender des Präsidiums) der Schweizerischen Gesellschaft für Innere Medizin sowie Direktor und Chefarzt Klinik und Poliklinik für Allgemeine Innere Medizin des Universitätsspitals Bern.

Die 77. Jahresversammlung der Schweizerischen Gesellschaft für Innere Medizin SGIM findet vom 13. bis 15. Mai 2009 in Basel statt. Informationen und Anmeldung unter www.congress-info.ch/ sgim2009. medizin und es werden gezielt junge Kolleginnt endlich auch im Bereich der Hausarztmedizin abzuheben! Die SGIM-Jahresversammlung 2009 lässt uns hautnah dabei sein. Nachdem bei uns jahr(zehnt)elang über die Hausarztforschung vornehmlich geredet wurde, findet sie jetzt wirklich statt: An allen medizinischen Fakultäten entstehen Institute und zum Teil Professuren für Hausarztrancer gen im Bereich Hausarztmedizinforschung aufgebaut. Die SGIM-Jahresversammlung ist auch ein Schaufenster für die Resultate dieser Entwicklung!

- Wir haben das Privileg, in einer Zeit zu leben, in der die Umsetzung von (klinischen) Forschungsresultaten in die Praxis sehr schnell gehen kann, wie die HIV-Forschung als eindrückliches Beispiel zeigt (von der Feststellung eines Hemmhofes in einer Bakterienkultur um eine Pilzkolonie durch A. Fleming bis zur ersten Anwendung von Penicillin beim Menschen brauchte es dagegen 13 Jahre!). Eine Weiter- bzw. Fortbildungsveranstaltung wie die diesjährige SGIM-Jahresversammlung erlaubt dem Kliniker, sich frühzeitig über Forschungsresultate, die für die Praxis schon in naher Zukunft relevant werden, zu informieren.

- Eine SGIM-Jahresversammlung ist auch ein Ort der Begegnung mit Kolleginnen und Kollegen. Wir sind ja nebst den medizinischfachlichen Aufgaben, denen wir uns gerne stellen, zunehmend mit administrativen und standespolitischen Problemen konfrontiert (TARMED, Labortarif, DRG u.a.), mit denen wir uns etwas weniger begeistert auseinandersetzen. An unserer Jahresversammlung mit voraussichtlich über 3000 Teilnehmern bietet sich Gelegenheit, sich zusammenzufinden und abseits des Praxis- oder Spitaldrucks miteinander über gemeinsame Sorgen und Nöte zu sprechen (da ja geteiltes Leid bekanntlich immer noch höchstens halbes Leid ist). Die SGIM-Jahresversammlung hat also auch hier eine ganz wichtige, persönlich-menschliche Funktion.

Ich hoffe, meine Ausführungen haben die letzten wenigen Zauderer überzeugt, an der SGIMJahresversammlung 2009 in Basel teilzunehmen. Von Erasmus von Rotterdam, der von 1524 bis 1529 in dieser Stadt gelehrt hat, stammt das Zitat: «Es tut halt so sauwohl, keinen Verstand zu haben.» Nun, wir Internisten (und selbstredend auch die Fachärzte der mit der Inneren Medizin verwandten Disziplinen!) haben Verstand und nehmen daher an der 77. SGIM-Jahrestagung in Basel teil.

Ich freue mich sehr, Sie in Basel zu treffen

Ulrich Bürgi *

Ulich Buigit 